\title{
A Review on Optimization of the Process
} Parameters in Friction Stir Welding of

\section{Aluminium Alloys (AA6082 and AA6105) by Taguchi Technique.}

\author{
Sourabh Rohilla ${ }^{1}$, Upender Dhull ${ }^{2}$
}

\footnotetext{
${ }^{1}$ Research Scholar, Department of Mechanical Engineering, UIET, Kurukshetra University Kurukshetra, India

${ }^{2}$ Asst. Profes sor, Department of Mechanical Engineering, UIET, Kurukshetra University Kurukshetra, India
}

\begin{abstract}
This study is describing a simple and systematic methodology for optimizing the Process parameters of friction stir welding (FSW) of (AA6105 and AA6082) aluminium alloy using Taguchi technique. The main focus of this review paper is to discuss FSW principle, process parameter and mechanical properties. The current study focuses on the friction stir welding of wrought aluminium alloys 6082 and aluminium alloy 6105 that are commonly used in the structural and automotive industries. Apart from this paper FSW process has been done on various aluminium alloys but dissimilar friction stir welding of these two materials are not reported in their research. A systematic study has been performed on the joint properties on the dissimilar welding of the selected materials and their relationships between various parameters.
\end{abstract}

Keywords-Friction Stir Welding, AA6082, AA6105, Process Parameters, Taguchi

\section{Introduction}

Aluminium is a soft, light-weight metal recognized in dull silvery white look. Aluminum has become especially a supreme metal within the nineteenth century due to its lightweight weight and corrosive resistant properties. . It is 3 times lighter than steel and still; it offers high strength in its alloy type. It has lower in density $\left(2.7 \mathrm{~g} \mathrm{~m} . / \mathrm{cm}^{3}\right)$, low in melting temperature $\left(\mathrm{T}_{\mathrm{m}}=660^{\circ} \mathrm{C}\right)$ and face centered cubic crystal (FCC) structure that makes Alu minumelement to be created and fabricated a lot of simple and with less value. Pure aluminum is soft and has a low strength of 40-50 MPa in tempered condition. It is reinforced by undergoing many processes like alloying and heat treatment. Alu minu malloys offer a good vary of capability and applicability due to its many advantages that makes the material in demand in fabrication industries, automobile industries, aeronautical industries and other structural applications of transport and buildings. If we are talking about $6 \mathrm{xxx}$ series $6 \mathrm{xxx}$ series represent underneath the group of molded component metal alloys with Silicon and Magnesium is the major alloying elements. These alloys represent a major portion of architectural and structural applications attributable to its wonderful formability when high strength to weight ratio is crucial. Aluminium alloy 6082 is one of the foremost widely used $\mathrm{Al}$ alloys due to its formability, good strength and high corrosive resistance. Aluminiu m alloy 6105 is heat treatable forged $\mathrm{Al}$ alloy with the composition of $\mathrm{Si}, \mathrm{Mg}$, and copper as major alloying parts.

\subsection{Base Material Properties}

Table.1: Chemical composition of the base materials

\begin{tabular}{|l|l|l|l|l|l|l|l|l|l|}
\hline Material & Mg & Mn & Fe & Si & Cu & Cr & Ti & Zn & Al \\
\hline AA6082 & 0.877 & 0.578 & 0.381 & 1.13 & 0.0389 & 0.0343 & 0.0160 & 0.0089 & remaining \\
\hline AA6105 & $\mathbf{0 . 5 1 3}$ & $\mathbf{0 . 0 1 0 2}$ & $\mathbf{0 . 1 3 5}$ & $\mathbf{0 . 6 2 4}$ & $\mathbf{0 . 0 0 9 4}$ & $\mathbf{0 . 0 0 3 0}$ & $\mathbf{0 . 0 2 0 6}$ & $\mathbf{0 . 0 1 3 9}$ & remaining \\
\hline
\end{tabular}


Table.2: Mechanical properties of the base materials

\begin{tabular}{|c|c|c|c|}
\hline Material & Yield Strength (MPa) & $\begin{array}{c}\text { Ultimate Tensile } \\
\text { Strength(MPa) }\end{array}$ & \% Elongation \\
\hline AA6082 & 279 & 330 & 12 \\
\hline AA6105 & 170 & 280 & 11 \\
\hline
\end{tabular}

\subsection{FRICTION STIR WELDING OF ALUMINIUM ALLOYS}

Friction stir welding (FSW) is a solid state welding process invented and patented by The Welding Institute (TWI) Cambridge, U.K. in 1991 [11]. If we are talking about the standard fusion weld ing process, where the material is to be joined is liquefied and resoldified, FSW works on the principle of complete material deformation. However, the material is joined within the solid state by the heat generated within the interface by the friction and by the flow of materials as the result of intense stirring action. As the compressive force increase by the tool the diffusion process start and this diffusion is responsible for the joining of the metal. And the metal join by diffusion is defect free.

\section{Direction of}

\section{Axial force tool rotation} of welding Joint Line

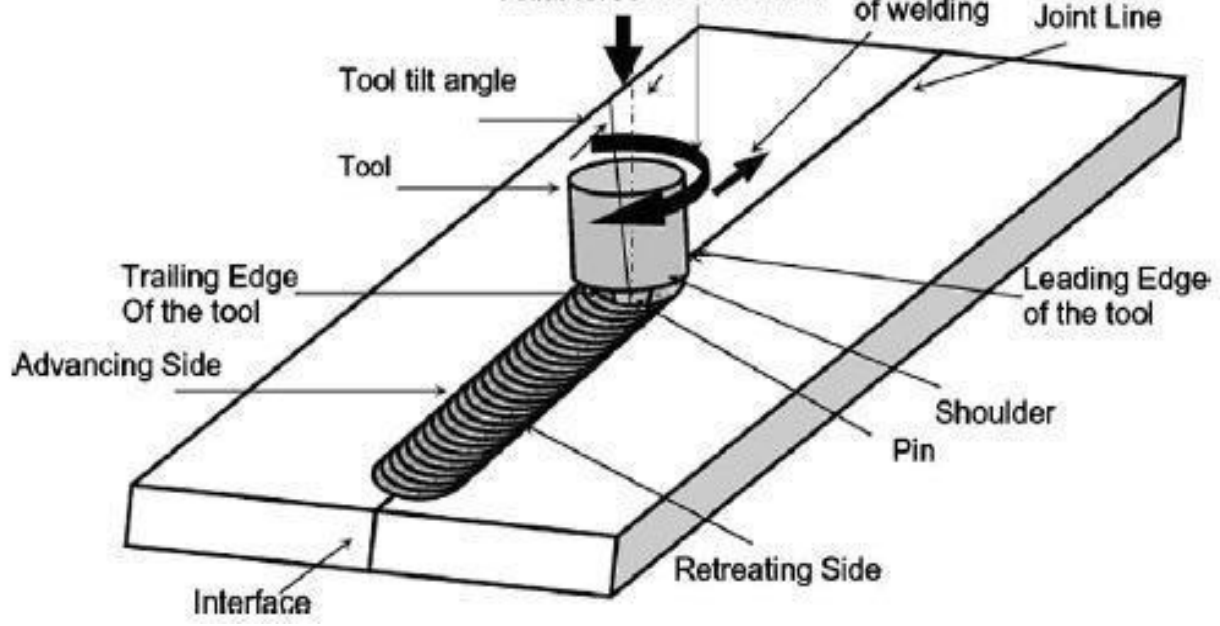

Fig.1: Schematic representations offriction stir welding process

\subsection{Advantages of Friction Stir Welding}

Some of the unique advantages of the FSW are discussed in this section

\section{Green Technology}

FSW is called as the green energy welding due to its environmental friendliness and versatility. Unlike fusion weld ing process, FSW is an autogenous process. FSW does not use flux, shielding gases, and filler material.

\section{Improved Weldability}

FSW has been successfully employed in joining materials that are considered to be unweldable by conventional welding techniques. Few cast metals that are difficult to weld due to the formation of brittle phases and cracking are also succes sfully joined by FSW.

\section{Safety}

FSW is considered as a safe process as it devoid of toxic fumes or the spatter of molten material. Contradicting to the conventional welding, there are no ultraviolet or electromagnetic radiation hazards as the absence of the arc removes these hazards from the process.

\section{Reduced distortion}

As the friction stir welding process is conducted below the re crystallization temperature, it reduces the longitudinal and transverse distortion. Thus the absence of fusion removes much of the thermal contraction associated with solidification and cooling, leading to significant reductions in distortion. Reducing distortion, in turn, reduces time and money in the post-weld treatment process of the material in the manufacturing industry.

\section{Improved appearance}

FSW gives a good weld appearance after weld ing. It does not require high joint preparation for welding. It does not involve expensive machining after weld ing. The root side of the weld and the weld interface are virtually invisible after painting.

\section{Improved mechanical properties}

The results of the tests like tensile tests, hardness test, fatigue and bend tests show better improvement in the 
mechanical properties when compared to other fusion processes like TIG and MIG.

\section{Easily automated}

FSW is a robust process and can be easily automated on simple milling machines, thus lowering setup costs. High skilled labor is not required like conventional fusion welding. It can be operated in all position (vertical, horizontal, inclined).

\subsection{Applications of FSW}

a) Shipbuilding and marine industries

- Panels for decks, sides

- Offshore accommodations

- $\quad$ Masts and booms for sailing boats

- $\quad$ Oil rig panels, bulkheads, and floors

- Marine structures

- Aluminium extrusions and patrol vessels

b) Aerospace Industry

- The aerospace industry in friction stir weld ing has been replacing riveting by offering lightweight structures.

- $\quad$ Large tanks for satellite launch vehicles

- Aviation Fuel tanks

- Repair of fusion welds

- $\quad$ Aircraft fuselages and wings

- Military and scientific rockets

c) Railway

- High-speed trains made from aluminium extrusions

- Modern railway carriage

- High-speed trains, railway tankers, goods wagons,

- Trams

c) Automotive

- Suspensions and pistons

- $\quad$ Engine chassis cradles

- Wheel rims

- Doors and bonnet

- Tailored Blanks

- The housing of fuel tanks, truck bodies, mobile cranes

- Armor plate vehicles

- Buses and other transport vehicles

- Motorcycle and bicycle frames

d) Other industry sectors

- Aluminium extrusions for interior and exterior decorations

- Aluminium bridges

- $\quad$ Air conditioning units

- Window frames and aluminium pipelines

- Vacuum vessels

\section{LITERATURE SURVEY}

The objective of the literature review is to exhibit and highlight previous research various researchers field of friction stir welding of aluminum alloys. The important aspect of formulating a problem in the research work with the clear objective is to have a deep insight into the literature survey. The selected reviews of the literature survey presented are

1. FSW process analysis

2. Mechanical Properties

\subsection{LITERATURE}

L.E Murr, R.D Flores et al.,(1998) performed friction stir welding on aluminum alloys (AA1100 \& AA6061).In this, they review very recent FSW works on microstructure comparison in several alu minu malloys. During studied they find that microstructure of aluminum AA1100 have initial large columnar grain and show dynamic contrast rather than aluminum AA6061.

Cavalier et al., (2006) conducted friction stir welding on AA6056and he observed the effect of welding parameters on mechanical properties and found their highest value. The weld ing speeds and rotating speed is 40 and $56 \mathrm{~mm} / \mathrm{min}$ and $(500 \mathrm{rpm})$. As the welding speed and rotational speed has increased the ductility is decreased. The value of tensile strength was extreme at rotational speed $800 \mathrm{rpm}$ and welding speed $80 \mathrm{~mm}$.

A Scialpi et al., (2007) studied the influence of shoulder geometry on microstructure and mechanical properties of friction stir welded 6082 alloys. They conducted a bending test of the welded specimen to discover the defect like root flaw and kissing bond. FSW gives a noticeable change in microstructure .Tool analysis has been carried out on AA6082.The thickness of the sheet is $1.5 \mathrm{~mm}$ the rotating speed is $1810 \mathrm{rpm}$ and feed rate $460 \mathrm{~mm} / \mathrm{min}$ and tool with shoulder shows different crown cavity.

P.G.M.P.Moreira et al (2008) performed friction stir weld ing on alu minu m 6082 -t6 and 6061-t 6 and studied the fatigue crack growth propagation rate of the friction stir welded material is lower than the base material. The alu minu 6082 and 6061 shows similar crack propagation rate. The SEM analysis has been done for microstructure change.

Lakshminarayanan and Balasubramanian (2008) explore the different process parameter on tensile strength and yield strength. They applied the Taguchi approach to find the optimum condition at which they both term having high value. The material that is chosen for fsw is RDE-40 alu minu m alloy. It also is noted that rotation speed, weld ing speed are the main parameter for calculating the tensile 
strength and yield strength.

Priya et al (2009) studied the effect of post weld heat treatment on the microstructure and mechanical properties of dis similar friction stir elements of AA6061 and AA2219. During their study, it is found that hardness has the main effect on the weld zone and when we compare HAZ with direct post weld zone there is no effective improvement. But at $555^{\circ} \mathrm{c}$ and aging te mp $165^{\circ} \mathrm{c}$, there is some improvement in hardness off weld zone and she also studied that postweld aging has not any influence on hardness.

G.Padmanaban, V.Balasubramanian (2009) has done an experiment using friction stir welding on AZ31B magnesium alloys. During this, they investigate the selection of FSW tool pin profile shoulder diameter and material. They found that the joint fabricated by high carbon steel tool with threaded profile and shoulder diameter of $18 \mathrm{~mm}$ having high tensile properties and absence of defects in nugget region.

Chan bin sheen et al (2011) performed friction stir welding in 6082 and 5083. They study the microstructure and electrochemical behavior of the friction stir welding on the dissimilar weld. The microstructure of FSW weld consists of finer grain than any other welding. At rotational speed $300 \mathrm{rpmand}$ transverse speed $1.6 \mathrm{~mm} / \mathrm{min}$ tool tilt angle $3^{\circ}$.The average corrosion rate is a min of two parent metal.

Ehab a. El-Danaf et al (2013) performed friction stir welding on AA 6082 with three different combinations of feed rate $(90,140,224) \mathrm{mm} / \mathrm{min}$ rotational speed $(850,1070$, 1350) rpm. During the experiment, they studied the microstructure and mechanical properties of friction stir welded 6082. The maximum grain size is $2.8 \mu \mathrm{m}$ at post weld heat condition at 175 degree for $12 \mathrm{~h}$ alu minum 6082 is more influence in recovering joint strength.

HM Anil Kumar et al (2014) has studied FSW, its process parameters, the principle of operation, advantage \& disadvantages. During its study, they found that principle of FSW and essential factors that affect the quality of weld and the critical analysis realize the possible research works on other than aluminum alloys such as mild steel (work piece) and cubic boron nitride (tool), with same process parameters.

Pavan Kumar et al., (2016) studied the comparison of microstructure and mechanical properties of friction stir welding of aluminum 6082 with different tool profile .rotational speed is $1400 \mathrm{rpm}$ welding speed is constant $90 \mathrm{~mm} / \mathrm{min}$.electron microscope is used to test the fracture surface. During analysis, they found that mechanical and metallurgical properties are affected by tool profile.

Dhananjaya Av via, DK Deried (2017) performed FSW on AA6082 During the study the effect of process parameter on mechanical and mic ro structured properties of similar AA6082 joint is studied. After study they found that the value of micro hardness is weld zone at $48 \mathrm{~mm} / \mathrm{min}$ are higher than other welding speed, increase welding speed leads to the increase in tensile strength.

S.Verma et al (2017) studied the temperature distribution deriving FSW of Aluminum 6082 alloy, the temp distribution is captured using thermocouple during FSW of 6082 for varying this angle the max temp is attained on when tilt angle in $2^{\circ}$ rotation speed $600 \mathrm{rpm}$ well $30 \mathrm{sec}$.

M.V.R.Durga Prasad, Kiran Kumar Namal (2018) performed friction stir welding on AA5083 and AA6063 to study the process parameter optimization by ANOVA. The process parameters considered are rotation speed, welding speeds, and tilt angle. During their optimization, they find that welding speed has the major factor. The maximum value of hardness at tool rotation speed $1200 \mathrm{rpm}$, weld ing speed of $80 \mathrm{~mm} / \mathrm{min}$ and tilt angle of $0^{\circ}$.

Malkeshwar, Vinodkumar et al (2018) performed a test using FSW on 5mm plates of aluminium AA6061, AA6082 and AA19500 to determine the micro hardness \& micro structural of joint. Different values of welding speed, rotation speed \& shoulder diameter were taken. During studied they find that tensile strength of similar metal is more than dissimilar metal.

K. N. Wakchaure et al (2018) shows the experimental and numerical investigation of friction stir welding on AA6082T6. The objective of this research is to multi-response optimization of FSW for an optimal parametric combination to yield favorable tensile strength and impact. During study they find that tool rotation speed and welding speed have maximum influence on mechanical properties rather than tool tilt angle.

\section{CONCLUSIONS}

There are many kinds of literature available on the study of these two materials. The dissimilar friction stir welding of these two materials are not reported in their research work. In this dissimilar friction stir welding of AA6082 and AA6105 is reviewed. The effect of the process parameters on the mechanical properties of AA6082 and AA6105 is yet to be reported. The present work aims at studying the effect of process parameters on the mechanical properties of the FS welding of aluminiumalloys AA6082 and AA6105.after reviewed the past literature it is also found that rotational speed, welding speed and tilt angle are the major process parameters. With changing the welding speed and rotational speed there is change in the hardness and tensile strength. 


\section{REFERENCES}

[1] Cavaliere, P, Nobile, R, Panella, FW \& Squillace., 2006. "Mechanical and microstructural behaviour of 2024-7075 aluminium',,. International Journal of Machine Tool , pp.588-594.

[2] Elangovan, $\mathrm{K} \&$ Balasubramanian, V., 2009," 'Influences of post-weld heat treatment on tensile properties of friction stir-welded AA6061 aluminum alloy joints",. Material Characterisation, vol.59, pp. 1168-1177.

[3] Lakshminarayanan, AK, Balasubramanian, V \& Elangovan, K., 2008,"Effect of weld ing processes on tensile properties of AA6061 alu miniu m alloy joints". International Journal of Advanced Manufacturing technology, vol.50, no.17, pp.4275-4292.

[4] A. Scialpi, L. D.,2007,"Influence of shoulder geometry on microstructure and mechanical properties of friction stir welded 6082 aluminium alloy'. Elsevier, 1124-1129.

[5] P.G.M.P Moreira., 2008,"Fatigue crack growth in friction stir welds of 6082-T6 and 6061-T6 alu miniu m alloys". Theoretical and Applied Fracture Mechanics , 169-177.

[6] Changbin Shen., 2011, "Microstructures and electrochemical behaviors of the friction stir welding', Journal of Environmental Sciences 2011, 23(Supplement), S32-S35.

[7] S, verma, \& Meenu., 2017,"Study on temperature distribution during Friction Stir Welding of 6082 aluminum alloy', Materials Today: Proceedings 4 , 1350-1356.

[8] Dhananjayulu, Avula., 2017, "Effect of Welding Speed on Mechanical Properties of Friction Stir'. Applied Mechanics and Materials, Vol. 877, pp 98103.

[9] M.V.R, Durga Prasad., 2018,"Process Parameters Optimization in Friction Stir Welding by Anova'. Materials Today: Proceedings 5 , 4824-4831.

[10] Hardik J, Chauan., 2016, “Experimental Investigation and Non Destructive Testing of FSW Aluminium Alloy AA6082', International Research Journal of Engineering and Technology (IRJET), 2656-64.

[11] Thomas et al., 1991, "Friction Stir Butt Welding", International patent Applications No. PCT/GB 92/02203, GB patent No.9125978.8 and U.S.PatentNo.5460317. 